\title{
Effects of Dangguibuxue decoction on rat glomerular mesangial cells cultured under high glucose conditions
}

\author{
Xiao-Dan Ren ${ }^{\dagger}$, Ying-Wen Zhang ${ }^{*}{ }^{\dagger}$, Xiu-Ping Wang and Ya-Rong Li
}

\begin{abstract}
Background: Dysfunction of glomerular mesangial cells (GMCs) plays an important role in pathogenesis of diabetic nephropathy. Here, we investigated the effects of Dangguibuxue decoction (DBD), an herbal traditional Chinese medicinal (TCM) formula composed of Astragali Radix and Angelicae Sinensis Radix, on GMC proliferation and fibrogenesis under high-glucose $(\mathrm{HG})$ conditions.

Methods: Sixty male Sprague Dawley rats were divided into 5 groups and administered intragastric 0.9\% saline, low concentration DBD (DBD-L, $1.75 \mathrm{~g} / \mathrm{kg} / \mathrm{d}$ ), middle concentration DBD (DBD-M, $3.5 \mathrm{~g} / \mathrm{kg} / \mathrm{d})$, high concentration DBD (DBD-H, $7.0 \mathrm{~g} / \mathrm{kg} / \mathrm{d})$ and gliclazide $(\mathrm{GL}, 2 \mathrm{mg} / \mathrm{kg} / \mathrm{d})$, respectively, for 1 week, and then their sera were obtained. Rat mesangial cells (HBZY-1 cells) were treated with these sera under HG condition $(30 \mathrm{mmol} / \mathrm{L}$ ).

Results: The proliferation of GMCs under HG conditions was significantly greater than that under normal glucose condition. Low concentration DBD (DBD-L) inhibited proliferation of GMCs after 72-h incubation $(P<0.01)$, while high concentration DBD (DBD-H) inhibited GMCs proliferation at 24, 48 and 72 time points $(P<0.01)$. There was no significant difference between the inhibitory effect of DBD-H and GL sera on GMC proliferation $(P>0.05)$. Furthermore, all concentrations of DBD (DBD-L, DBD-M and DBD-H) significantly decreased the protein expression of $\boldsymbol{a}$-SMA( $\boldsymbol{a}$-smooth muscle actin) $(P<0.01)$, an indicator of interstitial fibrosis of GMCs. Finally, DBD-L, DBD-M, DBD-H sera obviously inhibited the increase of HYP (hydroxyproline)secretion under HG condition $(P<0.01)$.

Conclusion: Our results demonstrate an inhibitory effect of DBD extract on proliferation and fibrogenesis of GMCs under HG conditions. The potential role of DBD in the treatment of diabetic neuropathy merits further investigation.
\end{abstract}

Keywords: Cell proliferation, Complementary therapies, Diabetic nephropathies, Mesangial cells

\section{Background}

Diabetic nephropathy is the most common cause of end stage renal disease [1]. The condition is associated with typical renal morphological/ultrastructural changes, such as collapse of the charge barrier at the glomerular basement membrane (GBM), excessive amassing and expansion of extracellular matrix (ECM) components, and advanced interstitial fibrosis [2]. Although the precise pathogenetic mechanism of diabetic nephropathy is not fully elucidated, dysfunction of glomerular mesangial

\footnotetext{
* Correspondence: hhao3838@sina.com

'Equal contributors

Department of Integrated Traditional Chinese and Western Medicine,

Zhongnan Hospital of Wuhan University, Wuhan University, Wuhan 430071, China
}

(c) The Author(s). 2017 Open Access This article is distributed under the terms of the Creative Commons Attribution 4.0 International License (http://creativecommons.org/licenses/by/4.0/), which permits unrestricted use, distribution, and reproduction in any medium, provided you give appropriate credit to the original author(s) and the source, provide a link to the Creative Commons license, and indicate if changes were made. The Creative Commons Public Domain Dedication waiver (http://creativecommons.org/publicdomain/zero/1.0/) applies to the data made available in this article, unless otherwise stated. pathogenesis.

The dysfunction of GMCs in diabetic nephropathy is attributed to hyperglycemia-induced reprogramming of intracellular metabolism, changes in signaling pathway networks, excessive inflammation and production of reactive oxygen species (ROS) [3, 4].

Dangguibuxue decoction (DBD) is a herbal traditional Chinese medicinal (TCM) formulation that is composed of two herbs, Astragali Radix and Angelicae Sinensis Radix. Li Dongyuan described DBD for the first time in the Neiwaishang Bianhuo Lun in 1247 AD [5]. DBD has been used as a remedy for various diseases since more than 800 years in China [5]. DBD was shown to enhance 
bone regeneration [6], attenuate pulmonary fibrosis [7], stimulate proliferation of T-lymphocytes proliferation [8], and treat ailments by phosphorylating estrogen receptors [9]. Therapeutic effects of DBD in kidney-related disorders such as renal anemia and diabetic nephropathy have been recently reported [10-15]. DBD was shown to induce erythropoietin expression via hypoxia-inducible factor- $1 \alpha$ signaling pathway in the kidneys [16], to alleviate renal damage in streptozotocin-induced diabetic rats [10], and to reduce adriamycin-induced nephropathy in rats [17]. However, the pharmacological actions of DBD, and the underlying molecular mechanisms in the treatment of diabetic nephropathy, are largely unknown.

The present study is based on hypothesis that DBD may directly affect proliferation of GMCs and renal fibrogenesis, and thus treat diabetic nephropathy. The objective was to determine the effect of DBD on high glucoseinduced proliferation and fibrosis in cultured GMCs.

\section{Methods \\ Animals}

Sixty male Sprague Dawley rats ( 250 g) were purchased from the Wuhan University Animal Center (Wuhan, China) and maintained in specific pathogen-free conditions for 1 week prior to the experiment. All experimental procedures conformed to the NIH guidelines and were approved by the Ethical Review Board and Institutional Animal Care of Zhongnan Hospital of Wuhan University.

\section{Cell culture}

Rat mesangial cells line (HBZY-1 cell) was obtained from American Type Culture Collection (ATCC; Manassas, VA). HBZY-1 cells were cultured in RPMI-1640 medium (purchased from Hyclone, Logan, UT), supplemented with $10 \%$ fetal bovine serum (FBS, purchased from Gibco, Grand Island, NY), in a humidified chamber containing $5 \% \mathrm{CO}_{2}$ at $37^{\circ} \mathrm{C}$ as described previously [18].

\section{Preparation of DBD}

The decoction components (Astragali Radix and Angelicae Sinensis Radix) were prepared by Chinese pharmacy at the Zhongnan Hospital of Wuhan University. The decoction components were soaked in water for $30 \mathrm{~min}$ and then decocted to an extract solution $(2 \mathrm{mg} / \mathrm{mL})$. Highperformance liquid chromatography fingerprinting was used to control the quality of the decoction.

\section{Preparation of sera containing DBD}

The rats were randomly divided into five groups $(n=12$ per group) and administered intragastric $0.9 \%$ saline (control), low concentration DBD (DBD-L, $1.75 \mathrm{~g} / \mathrm{kg} / \mathrm{d}$ ), medium concentration DBD (DBD-M, $3.5 \mathrm{~g} / \mathrm{kg} / \mathrm{d}$ ), high concentration DBD (DBD-H, $7.0 \mathrm{~g} / \mathrm{kg} / \mathrm{d}$ ) and gliclazide (GL, $2 \mathrm{mg} / \mathrm{kg} / \mathrm{d}$, purchased from Servier Co. Ltd., France), respectively, for 1 week. At 1 week post-administration, rats were anesthetized using pentobarbital sodium $(40 \mathrm{mg} / \mathrm{kg})$, and blood samples collected from abdominal aorta $2 \mathrm{~h}$ after the last intragastric administration. Blood samples were stored at $4{ }^{\circ} \mathrm{C}$ for $4 \mathrm{~h}$, followed by their centrifugation at $3000 \mathrm{rpm}$ for $30 \mathrm{~min}$ to obtain sera.

Sera from the same group were mixed and inactivated by heating in a $56{ }^{\circ} \mathrm{C}$ water bath for $30 \mathrm{~min}$. The sera were then filtered using $0.22 \mu \mathrm{m}$ membrane filters and stored at $-80{ }^{\circ} \mathrm{C}$. Sera obtained from the five groups were labeled as control serum, DBD-L serum, DBD-M serum, DBD-H serum and GL serum, respectively.

\section{Drug administration in cells}

HBZY-1 cells were starved in low-serum RPMI-1640 medium (1\% FBS) for $24 \mathrm{~h}$. Subsequently, cells were divided into six groups: [1] 10\% FBS plus $10 \%$ normal serum in $5.6 \mathrm{mmol} / \mathrm{L}$ glucose (referred to as $\mathrm{NC}$ group); [2] $10 \%$ FBS plus $10 \%$ normal serum in $30 \mathrm{mmol} / \mathrm{L}$ glucose (HG group); [3] 10\% FBS plus 10\% DBD-L serum in $30 \mathrm{mmol} / \mathrm{L}$ glucose (HG + DBD-L group); [4] 10\% FBS plus $10 \%$ DBD-M serum in $30 \mathrm{mmol} / \mathrm{L}$ glucose (HG + DBD-M group); [5] 10\% FBS plus 10\% DBD-H serum in $30 \mathrm{mmol} / \mathrm{L}$ glucose (HG + DBD-H group); and [6] $10 \% \mathrm{FBS}$ plus $10 \% \mathrm{GL}$ serum in $30 \mathrm{mmol} / \mathrm{L}$ glucose (HG + GL group).

\section{Evaluation of cell proliferation}

Cell proliferation was evaluated by MTT (3-[4,5-dimethylthiazol-2-yl]-2, 5-diphenyltetrazolium bromide) assay as described elsewhere [18, 19]. Briefly, mesangial cells $\left(4 \times 10^{4}\right)$ were plated in 96-well culture plate and were allowed to adhere and spread for $24 \mathrm{~h}$ with $100 \mathrm{ul}$ of RPMI 1640 culture medium containing 1\% fetal bovine serum. Subsequently, cells were divided into six groups (NC, HG, HG + DBD-L, HG + DBD-M, HG + DBD-H and $\mathrm{HG}+\mathrm{GL}$ ) and treated as mentioned above for 24, 48 and $72 \mathrm{~h}$. At these time-points, $100 \mu \mathrm{L}$ of MTT solution (5 mg/mL in PBS) was added to the culture well and incubated again for $4 \mathrm{~h}$. The formazan crystals formed were solubilized in $100 \mu \mathrm{L}$ of dimethyl sulphoxide. The optical density of purple color was measured at $570 \mathrm{~nm}$ in a microplate reader. MTT was purchased from SigmaAldrich Co. LLC. (San Louis, MO).

\section{Measurement of Hydroxyproline}

Hydroxyproline (HYP) secreted by HBZY-1 cells into the culture medium was measured using a commercial enzyme-linked immunosorbent assay kit (\#A030-1, NanJingJianCheng Bioengineering Institute, Nanjing, China). The cells were seeded on to a 48-well plate and allowed to adhere overnight. Cells were starved for $24 \mathrm{~h}$ in low-serum RPMI-1640 medium (1\% FBS) to synchronize the cell population. The cells were then 
treated with the extracted sera for $72 \mathrm{~h}$, as described above. The cultured medium was collected and centrifuged at $2000 \mathrm{rpm}$ for $10 \mathrm{~min}$. After discarding the debris, the supernatant was collected for measurement, using ELISA kit, according to the manufacturer's instructions.

\section{Western blotting}

Cells were washed with cold phosphate-buffered saline (PBS) for three times, lysed in radioimmuneprecipitation assay (RIPA) buffer with protease inhibitor cocktail (purchased from Pierce, Rockford, IL), and used for Western blotting as described [20, 21]. About $30 \mu \mathrm{g}$ samples were run on $10 \%$ SDS-PAGE. The proteins were electrotransferred to nitrocellulose membranes for $3 \mathrm{~h}$. The nitrocellulose membranes were blocked in $5 \%$ milk for $1 \mathrm{~h}$ and then incubated overnight with rabbit anti-rat monoclonal antibody of $\alpha$-smooth muscle actin ( $\alpha$-SMA, \#ab32575, Abcam, Cambridge, MA) at $4{ }^{\circ} \mathrm{C}$. Then, the membranes were washed by tris-buffered saline with $1 \%$ tween 20 (TBST) for three times, and then incubated with horseradish peroxidase-conjugated secondary antibody against rabbit (KPL Gaithersbug, MD).

The membranes were washed three times and the immunoreactive proteins were detected by enhanced chemiluminescence (ECL kit, purchased from GE Healthcare LifeSciences, Piscataway, NJ) on radiographic films (purchased from Kodak, Rochester, NY). The films were scanned and the optical density of blots analyzed using Image J software (NIH). Glyceraldehyde-3-phosphate dehydrogenase (GAPDH) was detected with rabbit anti-rat polyclonal antibody (\#ab37168, Abcam) for internal loading control. Each experiment was repeated a minimum of three times.

\section{Statistical analysis}

Data were analyzed with GraphPad Prism-5 statistic software (La Jolla, CA). All values are presented as mean \pm Standard error of the mean (SEM). Between-group differences were assessed by Student's $t$-test or Analysis of Variance (ANOVA) followed by Tukey post-hoc test. $P<0.05$ was considered as statistically significant.

\section{Results}

DBD inhibits HG-induced proliferation of GMCs

We determined the effects of DBD on GMCs proliferation at 24, 48 and $72 \mathrm{~h}$. The proliferation of GMCs under HG conditions (HG group) was significantly greater than that under normal glucose condition (NC group), at all the three time-points (Fig. 1a). DBD-L serum did not affect the proliferation of GMCs (Fig. 1b). Although DBD-M serum failed to inhibit GMCs proliferation at the 24- and 48-h time-points, it significantly suppressed GMCs proliferation at $72 \mathrm{~h}$ (Fig. 1b). DBD-H serum had a remarkable inhibitory effect on proliferation

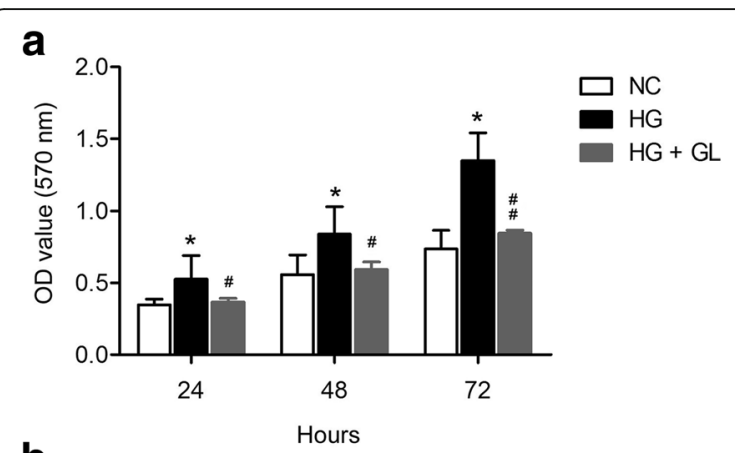

b
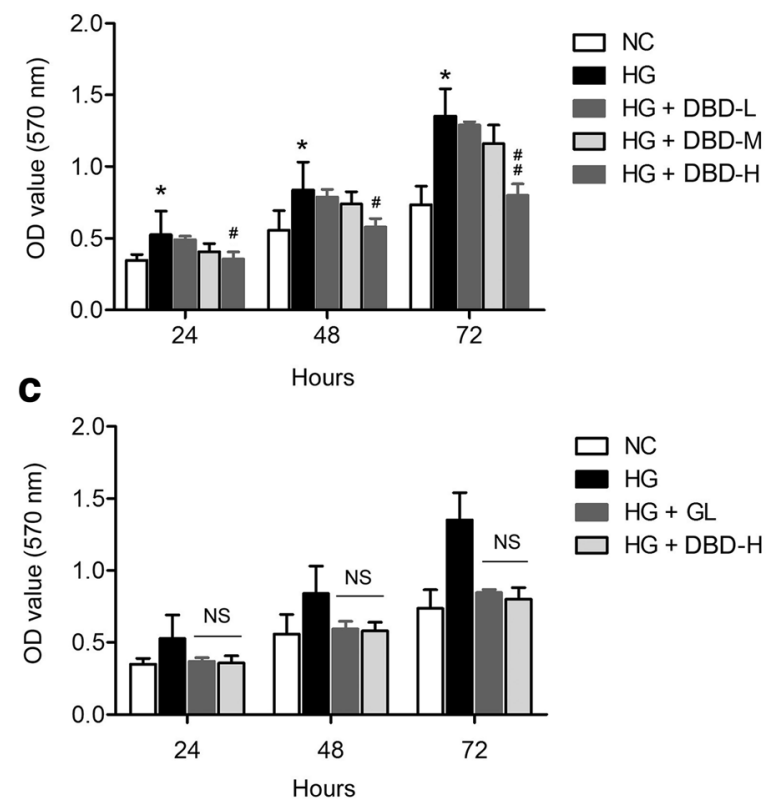

Fig. 1 Effects of DBD on proliferation of GMCs under high-glucose conditions (a) Proliferation of GMCs under high-glucose ( $\mathrm{HG}$ ) and HG plus gliclazide serum conditions at three time-points $(24,48$ and $72 \mathrm{~h}$ ); $\mathbf{b}$ Effect of DBD serum on proliferation of GMCs under HG condition at the three time-points; c Comparison of the inhibitory action of DBD serum and GL serum on proliferation of GMCs under $\mathrm{HG}$ conditions. ${ }^{*} P<0.05$ vs. NC (normal control); ${ }^{\#} P<0.05$ vs. HG. $N=6$ per group. DBD, Dangguibuxue decoction; GMCs, glomerular mesangial cells; GL, gliclazide

of GMCs at all three time-points (Fig. 1b). Moreover, there was no significant difference in the inhibitory effect of DBD-H serum and GL serum on the proliferation of GMCs (Fig. 1c).

DBD decreases HG-induced a-SMA expression in GMCs Upregulation of $\boldsymbol{\alpha}$-SMA is an indicator of interstitial fibrosis of GMCs, which has been shown to strongly correlate with the progression of diabetic nephropathy [22]. We found that the $\boldsymbol{\alpha}$-SMA protein expression in HGtreated GMCs was significantly higher ( $~ 8$-folds) than that in normal GMCs (Fig. 2a-b). All the three types of extracted sera (DBD-L, DBD-M and DBD-H) decreased the protein expression of $\boldsymbol{\alpha}$-SMA (Fig. 2a-b). GL also 

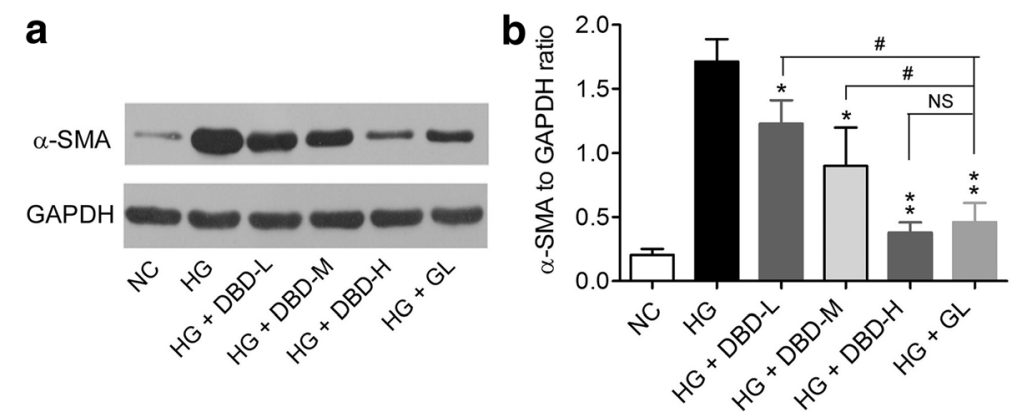

Fig. 2 Effects of DBD on a-SMA expression in GMCs. a Representative Western blot images showing a-SMA protein expression in cultured GMCs. GAPDH was used as a loading control; b Quantitative analysis of a-SMA protein expression in cultured GMCs. ${ }^{*} P<0.05$, ${ }^{* *} P<0.01$ vs. HG; ${ }^{\#} P<0.05$ vs. HG + GL. N = 4 per group. DBD, Dangguibuxue decoction; $a-S M A$, a-smooth muscle actin; GMCs, glomerular mesangial cells; GL, gliclazide; NS, not significant

reduced $\boldsymbol{\alpha}$-SMA protein expression (Fig. 2a-b). There was no significant difference between DBD-H serum and GL serum with respect to their inhibitory effect on $\boldsymbol{\alpha}$ SMA protein expression (Fig. 2a-b).

\section{DBD depresses HG-induced HYP secretion in GMCs}

HYP is another sensitive marker of renal fibrogenesis [23]. HG significantly enhanced HYP secretion from GMCs (Fig. 3). DBD-L, DBD-M, DBD-H and GL sera inhibited the effect of HG on HYP in GMCs (Fig. 3). This inhibitory action was most evident with DBD-H and GL sera (Fig. 3). In addition, there was no difference between DBD-H and GL sera in this respect (Fig. 3).

\section{Discussion}

DBD has been used as a clinical agent against renal dysfunction for more than 1, 000 year in China [10-15]. In recent years, several investigations have highlighted its

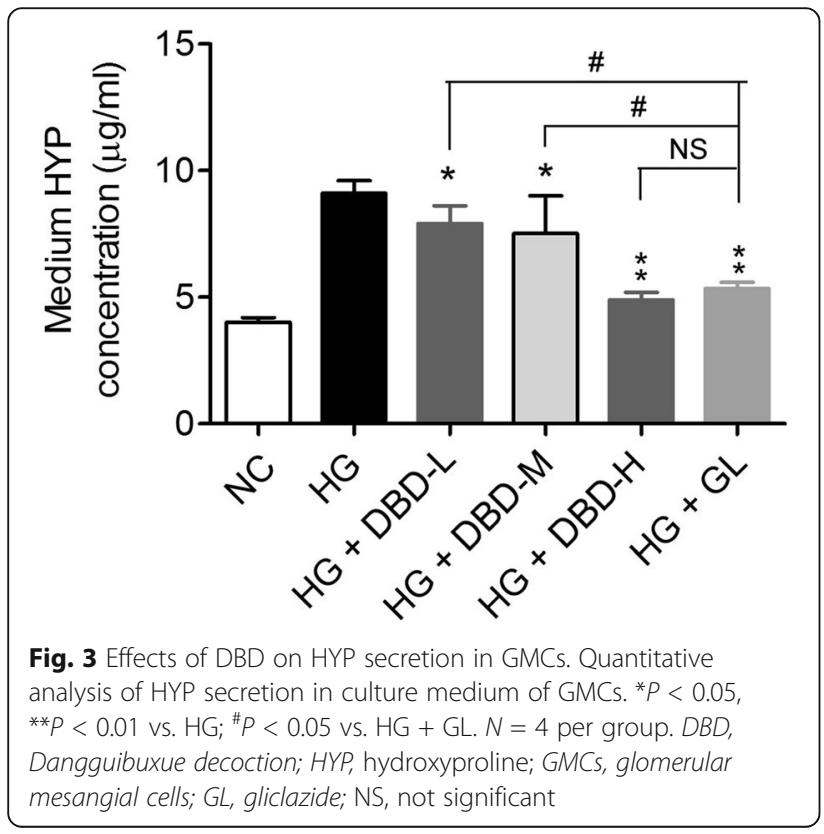

beneficial action on diabetic nephropathy. For example, Zhang et al. reported that DBD treatment attenuated the increases in fasting blood glucose, lipid, renal kidney/ body weight $(\mathrm{K} / \mathrm{B})$ ratio, urinary albumin excretion, and creatinine clearance rate in STZ-induced diabetic rats compared with benazepril [10]. In this study, we demonstrated that DBD inhibits proliferation of GMCs, suppresses $\boldsymbol{\alpha}$-SMA expression and reduces HYP secretion in cultured GMCs under high glucose conditions. These in vitro results reveal the inhibitory effects of DBD on the proliferation and fibrogenesis in GMCs, and suggest a potential role of $\mathrm{DBD}$ as a complementary therapeutic strategy for diabetic nephropathy.

The proliferation of GMCs is recognized as a major pathogenic event in the progression of diabetic nephropathy. Several studies have shown that the phenotype of cultured GMCs caused by HG environment mimics the pathophysiological changes in diabetic nephropathy [24]. Gene variations also critically contribute to the renal dysfunction in diabetes $[25,26]$. We found that high concentration DBD extract significantly inhibited GMCs proliferation at all three time-points (24, 48 and $72 \mathrm{~h}$ ), while medium concentration DBD extract only inhibited GMCs proliferation at $72 \mathrm{~h}$. Low concentration DBD extract did not seem to inhibit proliferation of GMCs.

These results indicate that the inhibitory effect of DBD on proliferation of GMCs is dose- and time-dependent. Gao et al. reported that DBD extract reversed high glucose-induced inhibition of endothelial cell migration and proliferation in vitro [27]. Ke et al. also showed that DBD inhibited HG-induced GMCs proliferation and reduced the expression of laminin and type IV collagen in GMCs [28]. Interestingly, DBD was previously reported to enhance proliferation of osteoblasts [29], T-lymphocytes [30], and bone marrow cells [31]. The discrepancy between the effects of DBD on cell proliferation may be due to the differences in culture conditions and cell types.

Fibrogenesis is another critical event in diabetic nephropathy $[2,3,32]$. At least four distinct cell types, including 
GMCs, bone marrow-derived progenitors, interstitial fibroblasts, and tubular epithelial cells, have been shown to participate in the metaplastic changes in diabetic kidney [33]. GMCs are a specialized type of vascular smooth muscle cells that constitute about $30-40 \%$ of the total glomerular cell population [34]. These provide structural support for glomerular capillaries and take part in the regulation of the glomerular filtration rate [34]. In normal conditions, GMCs do not express fibroblast-specific protein [33]. However, the behavior of GMCs changes under diabetic conditions. Hypertrophy of GMCs and mesangial matrix expansion are well-recognized characteristics in diabetic nephropathy [35]. These pathogenetic changes eventually lead to renal fibrosis, GBM thickening and ultimately obliteration of glomerular capillaries [35].

In the present study, DBD significantly attenuated the upregulation of $\alpha$-SMA in cultured GMCs by HG. $\alpha$-SMA is absent in normal mesangial matrix; and the upregulation of $\alpha$-SMA is a marker of myofibroblast fibrogenesis [35]. Moreover, $\alpha$-SMA also functions as a mechano transducer that responds to signals received at focal adhesions [35]. Thus, the inhibitory action of DBD on $\alpha$-SMA suggests its potential anti-fibrotic effect that may protect against diabetic nephropathy. HYP is a specific amino acid of collagen; and widely used as a marker for collagen production [36]. We also detected reduced HYP secretion in DBD-treated GMCs, which further supports the antifibrotic effect of DBD in diabetic nephropathy.

There are few limitations in our study. The inhibitory action of DBD on GMCs proliferation involves various signaling pathway activation [37-39]. For example, Park et al. reported that HG induces proliferation of GMCs via activation of intercellular adhesion molecule-1 (ICAM-1) [37] Wolf et al. demonstrated that p27 activation is required for the HG-induced proliferation of GMCs [38]. Danesh et al. showed that HG-induced Rho GTPase/p21 signaling contributes to the proliferation of GMCs [39]. We did not explore the underlying molecular mechanisms of the inhibitory action of DBD on the proliferation of GMCs and fibrogenesis. These interesting questions are worth pursuing in future investigations.

\section{Conclusion}

In summary, we demonstrated the inhibitory effect of DBD extract on proliferation and fibrogenesis of rat GMCs under high glucose conditions. The potential role of DBD in treatment and prevention of diabetic neuropathy merits further investigations.

\section{Acknowledgements}

Not applicable.

\section{Funding}

This work was supported by a grant from National Natural Science Foundation of China (No. 81373793).

\section{Availability of data and materials}

The datasets used an analysed during the current study available from the corresponding author on reasonable request.

\section{Authors' contributions}

Xiao-Dan Ren designed the study, conducted all searches, appraised all potential studies and wrote and revised the draft manuscript and subsequent manuscripts. Ying-Wen Zhang revised the draft manuscript and subsequent manuscripts. Xiu-Ping Wang $X$ assisted with the presentation of findings and assisted with drafting and revising the manuscript. Ya-Rong Li conceived and designed the study, assisted with searches, appraised relevant studies and assisted with drafting and revising the manuscript. All authors read and approved the final manuscript.

\section{Competing interests}

The authors declare that there is no conflict of interest regarding the publication of this paper.

\section{Consent for publication}

All patients or guardians, after reading, filled in and signed the consent form and agreed to participate in the study.

\section{Ethics approval and consent to participate}

The experimental protocol was established, according to the ethical guidelines of the Helsinki Declaration and was approved by the Human Ethics Committee of Department of Integrated Traditional Chinese and Western Medicine, Zhongnan Hospital of Wuhan University, Wuhan University, Wuhan, 430,071,China. Written informed consent was obtained from individual participants.

\section{Publisher's Note}

Springer Nature remains neutral with regard to jurisdictional claims in published maps and institutional affiliations.

Received: 13 December 2016 Accepted: 8 May 2017

Published online: 25 May 2017

\section{References}

1. Kato M, Natarajan R. Diabetic nephropathy-emerging epigenetic mechanisms. Nat Rev Nephrol. 2014;10(9):517-30.

2. Fineberg D, Jandeleit-Dahm KA, Cooper ME. Diabetic nephropathy: diagnosis and treatment. Nat Rev Endocrinol. 2013;9(12):713-23.

3. Sun YM, Su Y, Li J, Wang LF. Recent advances in understanding the biochemical and molecular mechanism of diabetic nephropathy. Biochem Biophys Res Commun. 2013;433(4):359-61.

4. Tuncdemir M, Ozturk M. Regulation of the Ku70 and apoptosis-related proteins in experimental diabetic nephropathy. Metabolism. 2016;65(10):1466-77.

5. Tzeng TF, Liou SS, Liu IM. The selected traditional chinese medicinal formulas for treating diabetic nephropathy: perspective of modern science. J Tradit Complement Med. 2013;3(3):152-8.

6. Wang WL, Sheu SY, Chen YS, Kao ST, Fu YT, Kuo TF, Chen KY, Yao CH. Enhanced bone tissue regeneration by porous gelatin composites loaded with the Chinese herbal decoction Danggui Buxue tang. PLoS One. 2015; 10(6):e0131999

7. Zhao P, Zhou WC, Li DL, Mo XT, Xu L, Li LC, Cui WH, Gao J. Total Glucosides of Danggui Buxue tang attenuate BLM-induced pulmonary fibrosis via regulating oxidative stress by inhibiting NOX4. Oxidative Med Cell Longev. 2015;2015:645814

8. Gao QT, Cheung JK, Li J, Jiang ZY, Chu GK, Duan R, Cheung AW, Zhao KJ, Choi RC, Dong TT, Tsim KW. A Chinese herbal decoction, Danggui Buxue tang, activates extracellular signal-regulated kinase in cultured Tlymphocytes. FEBS Lett. 2007;581 (26):5087-93.

9. Gao QT, Choi RC, Cheung AW, Zhu JT, Li J, Chu GK, Duan R, Cheung JK, Jiang ZY, Dong XB, Zhao KJ, Dong TT, Tsim KW. Danggui buxue tang-a Chinese herbal decoction activates the phosphorylations of extracellular signal-regulated kinase and estrogen receptor alpha in cultured MCF-7 cells. FEBS Lett. 2007;581(2):233-40.

10. Zhang YW, Xie D, Xia B, Zhen RT, Liu IM, Cheng JT. Suppression of transforming growth factor-beta1 gene expression by Danggui buxue tang, a traditional Chinese herbal preparation, in retarding the progress of renal damage in streptozotocin-induced diabetic rats. Horm Metab Res. 2006; 38(2):82-8. 
11. Ying-wen ZHANG, Dan X. Protective effect of Danggui Buxue decoction on the kidney of diabetis rats. Chinese Traditional Patent Medicine. 2005;1(5):35-7.

12. Wang $Y-j, L-q$ H, Sunc W, Lua Y, Wang X-q, P-q Z, L-b W, S-I C, Yang N-Z, Ma $\mathrm{H}-\mathrm{z}$, Gao J, Ping Li X-jT, Yuan F-H, Li J. Optimized project of traditional Chinese medicine in treating chronic kidney disease stage 3: a multicenter double-blinded randomized controlled trial. J Ethnopharmacol. 2012;139(3): 757-64.

13. Wei $M$, Xiong $P$, Zhang $L$. Effect of Chinese herbs on immunoglobulin a nephropathy: a randomized controlled trial. J Tradit Chin Med. 2013;33(1):65-9.

14. Liang $X-L$, Yuan J-Y. Effect of Chinese herbal compound on liver fibrosis in rabbits with schistosomiasis by B-ultrasound. Asian Pac J Trop Med. 2013; 6(8):658-62.

15. Liu J-Y, Chen X-X, Tang SC-W, Sze SC-W, Feng Y-B, Lee K-F, Yan-Bo K, Ying-wen $Z$. Chinese medicines in the treatment of experimental diabetic nephropathy. Chin Med. 2016;11:6. doi:10.1186/s13020-016-0075-Z

16. Zheng KY, Choi RC, Xie HQ, Cheung AW, Guo AJ, Leung KW, Chen VP, Bi CW, Zhu KY, Chan GK, Fu Q, Lau DT, Dong TT, Zhao KJ, Tsim KW. The expression of erythropoietin triggered by danggui buxue tang, a Chinese herbal decoction prepared from radix Astragali and radix Angelicae Sinensis, is mediated by the hypoxia-inducible factor in cultured HEK293T cells. J Ethnopharmacol. 2010;132(1):259-67.

17. Wei MG, Sun W, Xiong PH, Shao JD. Antifibrotic effect of the Chinese herbs modified Danggui Buxue decoction on adriamycin-induced nephropathy in rats. Chin J Integr Med. 2012;18(8):591-8.

18. Wang P, Xu TY, Guan YF, Tian WW, Viollet B, Rui YC, Zhai QW, Su DF, Miao CY. Nicotinamide phosphoribosyltransferase protects against ischemic stroke through SIRT1-dependent adenosine monophosphate-activated kinase pathway. Ann Neurol. 2011;69(2):360-74.

19. Wang P, Xu TY, Guan YF, Su DF, Fan GR, Miao CY. Perivascular adipose tissue-derived visfatin is a vascular smooth muscle cell growth factor: role of nicotinamide mononucleotide. Cardiovasc Res. 2009;81(2):370-80.

20. Wang P, Du H, Zhou CC, Song J, Liu X, Cao X, Mehta JL, Shi Y, Su DF, Miao CY. Intracellular NAMPT-NAD+-SIRT1 cascade improves post-ischaemic vascular repair by modulating notch signalling in endothelial progenitors. Cardiovasc Res. 2014;104(3):477-88.

21. Wang P, Yang X, Zhang Z, Song J, Guan YF, Zou DJ, Miao CY. Depletion of NAD pool contributes to impairment of endothelial progenitor cell mobilization in diabetes. Metabolism. 2016;65(6):852-62.

22. Saratlija Novakovic Z, Glavina Durdov M, Puljak L, Saraga M, Ljutic D, Filipovic T, Pastar Z, Bendic A, Vukojevic K. The interstitial expression of alpha-smooth muscle actin in glomerulonephritis is associated with renal function. Med Sci Monit. 2012;18(4):CR235-40.

23. Hewitson TD, Smith ER, Samuel CS. Qualitative and quantitative analysis of fibrosis in the kidney. Nephrology (Carlton). 2014;19(11):721-6.

24. Abboud HE. Mesangial cell biology. Exp Cell Res. 2012;318(9):979-85.

25. Mohammedi K, Patente TA, Bellili-Munoz N, Driss F, Le Nagard H, Fumeron F, Roussel R, Hadjadj S, Correa-Giannella ML, Marre M, Velho G. Glutathione peroxidase-1 gene (GPX1) variants, oxidative stress and risk of kidney complications in people with type 1 diabetes. Metabolism. 2016;65(2):12-9.

26. Monteiro MB, Thieme K, Santos-Bezerra DP, Queiroz MS, Woronik V, Passarelli M, Machado UF, Giannella-Neto D, Oliveira-Souza M, CorreaGiannella ML. Beta-2-microglobulin (B2M) expression in the urinary sediment correlates with clinical markers of kidney disease in patients with type 1 diabetes. Metabolism. 2016;65(6):816-24.

27. Gao D, Guo Y, Li X, Li X, Li Z, Xue M, Ou Z, Liu M, Yang M, Liu S, Yang S. An aqueous extract of radix Astragali, Angelica Sinensis, and Panax notoginseng is effective in preventing diabetic retinopathy. Evid Based Complement Alternat Med. 2013;2013:578165.

28. Ke HL, Zhang YW, Zhou BF, Zhen RT. Effects of Danggui Buxue tang, a traditional Chinese herbal decoction, on high glucose-induced proliferation and expression of extracellular matrix proteins in glomerular mesangial cells. Nat Prod Res. 2012;26(11):1022-6.

29. Dong TT, Zhao KJ, Gao QT, Ji ZN, Zhu TT, Li J, Duan R, Cheung AW, Tsim KW. Chemical and biological assessment of a chinese herbal decoction containing radix Astragali and radix Angelicae Sinensis: determination of drug ratio in having optimized properties. J Agric Food Chem. 2006;54(7): 2767-74.

30. Gao QT, Cheung JK, Li J, Chu GK, Duan R, Cheung AW, Zhao KJ, Dong TT, Tsim KW. A Chinese herbal decoction, Danggui Buxue tang, prepared from radix Astragali and radix Angelicae Sinensis stimulates the immune responses. Planta Med. 2006;72(13):1227-31.
31. Yang X, Huang CG, Du SY, Yang SP, Zhang X, Liu JY, Xian Q, Xu JH. Effect of Danggui Buxue tang on immune-mediated aplastic anemia bone marrow proliferation mice. Phytomedicine. 2014;21(5):640-6.

32. Li L, Chen L, Zang J, Tang X, Liu Y, Zhang J, Bai L, Yin Q, Lu Y, Cheng J, Fu P, Liu F. C3a and C5a receptor antagonists ameliorate endothelialmyofibroblast transition via the Wnt/beta-catenin signaling pathway in diabetic kidney disease. Metabolism. 2015;64(5):597-610.

33. Simonson MS. Phenotypic transitions and fibrosis in diabetic nephropathy. Kidney Int. 2007;71(9):846-54.

34. Migliorini A, Ebid R, Scherbaum CR, Anders HJ. The danger control concept in kidney disease: mesangial cells. J Nephrol. 2013;26(3):437-49.

35. Qian Y, Feldman E, Pennathur S, Kretzler M, Brosius FC 3rd. From fibrosis to sclerosis: mechanisms of glomerulosclerosis in diabetic nephropathy. Diabetes. 2008;57(6):1439-45.

36. Motawi TK, El-Maraghy SA, Senousy MA. Angiotensin-converting enzyme inhibition and angiotensin AT1 receptor blockade downregulate angiotensinconverting enzyme expression and attenuate renal injury in streptozotocininduced diabetic rats. J Biochem Mol Toxicol. 2013;27(7):378-87.

37. Park CW, Kim JH, Lee JH, Kim YS, Ahn HJ, Shin YS, Kim SY, Choi EJ, Chang YS, Bang BK. High glucose-induced intercellular adhesion molecule-1 (ICAM1) expression through an osmotic effect in rat mesangial cells is PKC-NFkappa B-dependent. Diabetologia. 2000;43(12):1544-53.

38. Wolf G, Schroeder R, Zahner G, Stahl RA, Shankland SJ. High glucoseinduced hypertrophy of mesangial cells requires p27(Kip1), an inhibitor of cyclin-dependent kinases. Am J Pathol. 2001;158(3):1091-100.

39. Danesh FR, Sadeghi MM, Amro N, Philips C, Zeng L, Lin S, Sahai A, Kanwar YS. 3-Hydroxy-3-methylglutaryl CoA reductase inhibitors prevent high glucose-induced proliferation of mesangial cells via modulation of rho GTPase/ p21 signaling pathway: implications for diabetic nephropathy. Proc Natl Acad Sci U S A. 2002;99(12):8301-5.

\section{Submit your next manuscript to BioMed Central and we will help you at every step:}

- We accept pre-submission inquiries

- Our selector tool helps you to find the most relevant journal

- We provide round the clock customer support

- Convenient online submission

- Thorough peer review

- Inclusion in PubMed and all major indexing services

- Maximum visibility for your research

Submit your manuscript at www.biomedcentral.com/submit
Biomed Central 